\title{
Volunteer Fire Chief Struck and Killed on Interstate Highway While Directing Traffic - Pennsylvania
}

\section{Executive Summary}

On April 27, 2013, a 45-year-old male volunteer fire chief (the victim) lost his life after being struck by a vehicle on an interstate highway. The victim had shut down the highway with his personal vehicle and was directing traffic onto an exit ramp. The victim's department was dispatched to assist a neighboring fire department working a motor vehicle incident. The victim's department was ordered by the incident commander to shut down both southbound travel lanes to allow for an aeromedical helicopter to land on the interstate. The victim responded to the scene in his personal vehicle, used it to block the southbound travel lanes, and diverted approaching traffic onto an off-ramp. A motorist, allegedly under the influence, drove around the victim's vehicle, striking and killing him. The victim was not wearing a high-

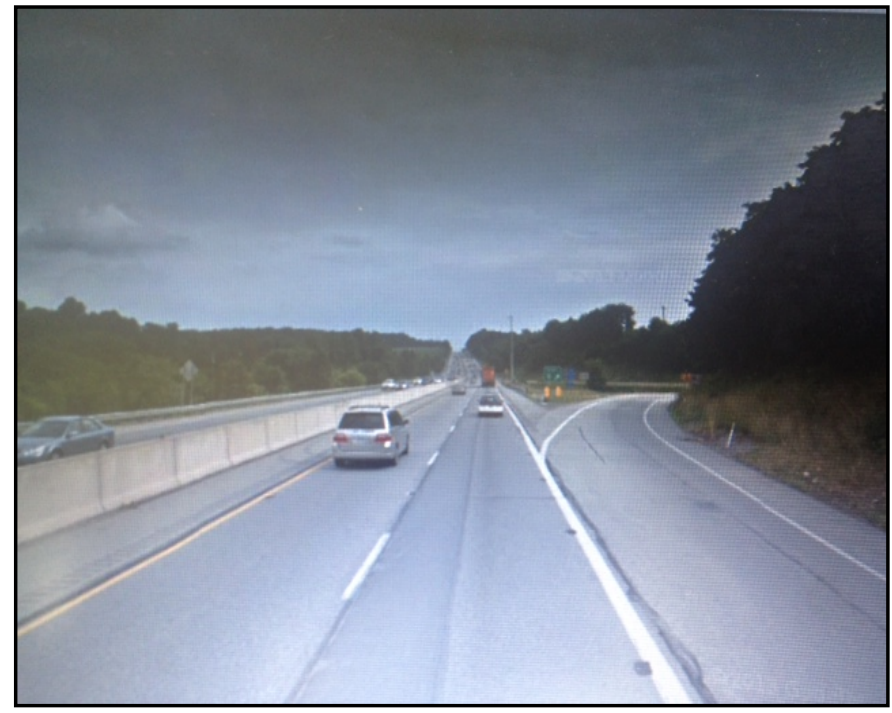

View of southbound lanes and off ramp where victim was struck and killed.

(Adapted from Google Earth ${ }^{\circledR}$ satellite image.) visibility retro-reflective vest and a traffic incident management area (TIMA) had not been established.

\section{Contributing Factors}

- Victim working in an unprotected travel lane

- Lack of advanced warning to oncoming traffic

- Inconspicuousness of victim and vehicle

- Alleged impaired motorist.

\section{Key Recommendations}

- Fire departments should ensure that emergency responders receive training and have adequate staffing, sufficient equipment, and appropriate procedures in place for responding to roadway emergency incidents 


\section{Volunteer Fire Chief Struck and Killed on Interstate Highway While Directing Traffic - Pennsylvania}

- Fire departments should ensure that standard operating procedures/guidelines include guidance on identifying and maintaining a safe location while working in or near moving traffic

- Fire departments should establish pre-incident plans and agreements regarding traffic control and incident management at roadway incidents with other fire departments, EMS, law enforcement, local or state departments of highways, and private sector responders

- Fire departments should ensure that apparatus equipped with high-visibility chevrons and reflective markings are used for blocking to enhance conspicuity and protection of emergency scenes while operating at highway incidents

- Fire departments should ensure that all personnel working at highway incidents wear the appropriate personal protective clothing and equipment, to include high-visibility retroreflective material

- Motorists should be attentive at all times, especially when approaching and driving through a traffic incident management area, so that they avoid striking emergency responders, other vehicles, or traffic control devices.

The National Institute for Occupational Safety and Health (NIOSH), an institute within the Centers for Disease Control and Prevention (CDC), is the federal agency responsible for conducting research and making recommendations for the prevention of work-related injury and illness. In 1998, Congress appropriated funds to NIOSH to conduct a fire fighter initiative that resulted in the NIOSH "Fire Fighter Fatality Investigation and Prevention Program" which examines line-of-duty-deaths or on duty deaths of fire fighters to assist fire departments, fire fighters, the fire service and others to prevent similar fire fighter deaths in the future. The agency does not enforce compliance with State or Federal occupational safety and health standards and does not determine fault or assign blame. Participation of fire departments and individuals in NIOSH investigations is voluntary. Under its program, NIOSH investigators interview persons with knowledge of the incident who agree to be interviewed and review available records to develop a description of the conditions and circumstances leading to the death(s). Interviewees are not asked to sign sworn statements and interviews are not recorded. The agency's reports do not name the victim, the fire department or those interviewed. The NIOSH report's summary of the conditions and circumstances surrounding the fatality is intended to provide context to the agency's recommendations and is not intended to be definitive for purposes of determining any claim or benefit.

For further information, visit the program Web site at www.cdc.gov/niosh/fire or call toll free 1-800-CDC-INFO (1-800-232-4636). 


\section{Volunteer Fire Chief Struck and Killed on Interstate Highway While Directing Traffic - Pennsylvania}

\section{Introduction}

On April 27, 2013, a 45-year-old male volunteer fire chief (the victim) lost his life after shutting down an interstate highway with his personal vehicle and directing traffic onto an exit ramp. On April 29, 2013, the U.S. Fire Administration notified the National Institute for Occupational Safety and Health (NIOSH) of this incident. On May 13 - 17, 2013, a safety and occupational health specialist from the NIOSH Fire Fighter Fatality Investigation and Prevention Program traveled to Pennsylvania to investigate this incident. The NIOSH investigator met with and interviewed the first assistant chief, fire department members involved with the victim’s incident, Pennsylvania State Police (PSP) investigators, and emergency medical services responders. The NIOSH investigator also spoke with the state fire commissioner.

The NIOSH investigator drove through and documented the incident scene. The NIOSH investigator also documented and photographed personal protective equipment (PPE) similar to that worn by the victim. The NIOSH investigator reviewed available training records for the victim, dispatch radio transcripts and audio recordings from the incident, and available standard operating guidelines (SOGs) of the fire department.

Due to an ongoing criminal trial, limited information concerning the incident was available to the $\mathrm{NIOSH}$ investigator. NIOSH has attempted to make this investigative report as detailed as possible.

\section{Fire Department}

At the time of this incident, this rural volunteer fire department operated out of a single fire station with 30 active members serving a population of over 1,200 within an area of about 10 square miles. The fire department had two engines, a rescue truck, and a support vehicle. This department responds to approximately 200 calls a year with 60-70 of those being highway-related incidents.

At the time of the NIOSH investigation, the fire department had established by-laws and SOGs dating back to 2002. These by-laws and SOGs were limited to day-to-day administrative operations and did not provide any guidance for operating at fire or EMS emergency incidents. Under the department's general policies found within their dispatch and response procedures, it stated, “...personal vehicles WILL NOT be used to physically block traffic and should be parked on the shoulder clear of the roadway."

Specific to this incident, the SOGs did not provide detailed guidance on establishing temporary traffic control zones or safely responding, operating, and leaving an interstate highway incident scene. Neither the fire department, nor law enforcement agencies, mutual aid departments, or the state highway department had established agreements or defined responsibilities for operating at highway incidents.

\section{Training and Experience}

The victim had been with this department for approximately 29 years holding the rank of fire chief for the last 12 years. The victim's training records were secured by the PSP as part of their investigation 


\section{Volunteer Fire Chief Struck and Killed on Interstate Highway While Directing Traffic - Pennsylvania}

and NIOSH was unable to review them. The first assistant chief for the department was able to tell the NIOSH investigator that the victim had once been a fire police officer for the State of Pennsylvania; however, he was not a fire police officer at the time of the incident. According to the department's assistant chief, individuals nominated by their department's as fire police officers are required to obtain training specific to responding and working at highway and roadway incidents. Additional information on the Pennsylvania Fire Police Officer Association can be found at http://firepolicepa.org/.

Neither the fire department nor the state fire commission have a required training program established for emergency responders on how to safely respond to a highway incident, how to correctly position on-scene apparatus, what traffic control devices should be used, how to deploy these devices, and how to take down the temporary traffic control zone once the incident scene has been cleared. However, there are training resources available through the Pennsylvania Fire Police Association, county fire police associations, and state fire academy.

\section{Equipment and Personnel}

The victim responded from his home in his personal 2006 maroon, pick-up truck (see Photo 1). The vehicle had a 20-inch red mini-light bar attached to the cab's roof that was activated at the time he was struck. Due to the PSP investigation, NIOSH was unable to document and photograph the vehicle.

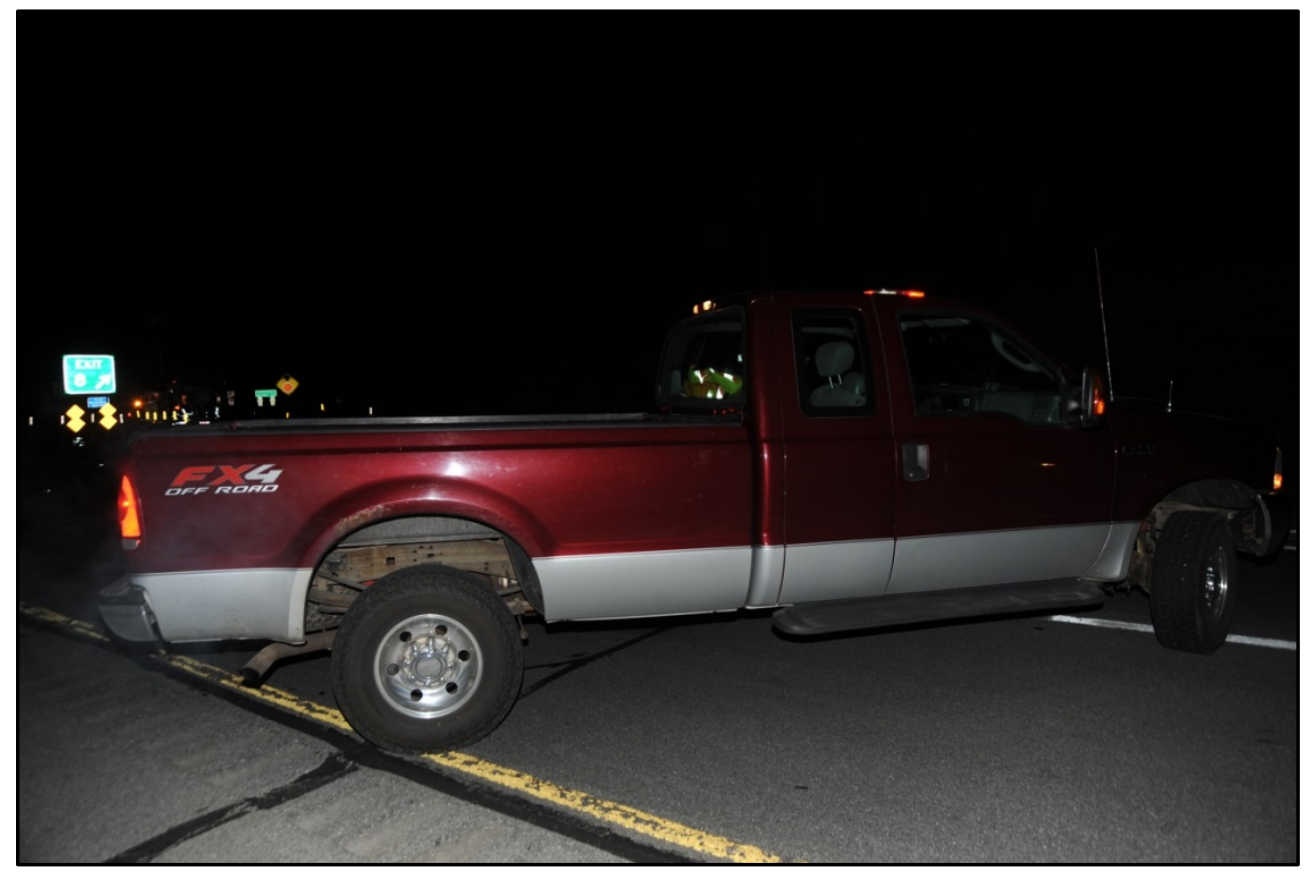

Photo 1. Photo of victim's vehicle.

(Photo courtesy of law enforcement.) 


\section{Volunteer Fire Chief Struck and Killed on Interstate Highway While Directing Traffic - Pennsylvania}

Additional personnel from the victim's department responded to the fire station to pick up a fire department vehicle. Engine 63 (E63) responded with two personnel on board. This unit arrived after the victim had been struck by the motorist. This department did not have traffic control devices such as warning signs and traffic cones.

\section{Timeline}

This timeline is provided to set out, to the extent possible, the sequence of events according to recorded and intelligible radio transmissions. Times are approximate and were obtained from review of the dispatch records, witness interviews, and other available information. Times have been rounded to the nearest minute. This timeline is not intended, nor should it be used, as a formal record of events.

- 0024 Hours

An additional engine from Station 58 was dispatched to establish a landing zone for an aeromedical helicopter at an earlier motor vehicle incident scene at mile marker five.

- 0025 Hours

Fire police from Station 63 (victim’s department) and Station 58 dispatched to the incident scene.

- 0029 Hours

E58 en route from their station.

- 0030 Hours

R59 en route from their station.

- 0033 Hours

Victim en route.

Dispatch advised the victim that command (of motor vehicle incident at mile marker five) requested to have the victim's engine shut down the southbound lanes at exit eight.

The victim confirmed request.

- 0036 Hours

E63 en route from their station.

Dispatch advised E63 to shut down the southbound lanes at exit 10.

- 0037 Hours

Dispatch confirmed that E63 should proceed to exit eight and not exit 10; acknowledged by E63.

- 0043 Hours

Victim advised dispatch that the southbound lanes of the interstate were shut down at exit eight. 


\section{Volunteer Fire Chief Struck and Killed on Interstate Highway While Directing Traffic - Pennsylvania}

- 0044 Hours

Dispatch received a cellular 9-1-1 call advising them that a pedestrian "walking across the street” had been struck after a motorist drove around “it” (victim’s vehicle).

- 0046 Hours

During the cellular 9-1-1 call personnel from E63 can be heard checking on the victim.

\section{Personal Protective Equipment}

Fire department personnel reported to the NIOSH investigator that the victim was wearing his issued structural firefighting coat (tan with standard high-visibility retro-reflective striping) and plain clothes. The victim's high-visibility retro-reflective vest was still in his personal vehicle. NIOSH was not able to inspect the victim's clothing or structural firefighting coat due to the ongoing criminal investigation.

\section{Weather and Road Conditions}

Weather this night was clear with temperatures in the upper 30s. The initial motor vehicle incident occurred in the northbound travel lanes approximately 2-3 miles south of where the victim was struck. This interstate highway had two northbound lanes and two southbound lines divided by a concrete jersey wall. Due to safety reasons, the NIOSH investigator was unable to attain measurements of the interstate highway where the incident occurred. The posted speed limit was 65 miles per hour.

\section{Investigation}

On April 27, 2013, a 45-year-old male volunteer fire chief (the victim) lost his life while directing traffic onto an exit ramp after shutting down an interstate highway with his personal vehicle. The victim's department was dispatched to assist with a motor vehicle incident that a neighboring department was working. The victim's department was requested by the incident commander to provide assistance in shutting down the southbound travel lanes at an exit north of the incident scene to allow an aeromedical helicopter to land on the interstate. The victim responded from his home in his personal vehicle while additional personnel responded to Station 63 to pick up an engine. According to the first assistant chief of the department, the fire chief was allowed to respond in his personal vehicle because it had been outfitted with a siren and oscillating red mini-light bar. The victim positioned his vehicle, with the mini-light bar turned on, at an angle from the fast lane. His vehicle's headlights remained on with side marker lights. The vehicle's headlights were not directed toward approaching southbound traffic. He apparently intended to block oncoming traffic and allow motorists the opportunity to divert from the interstate and onto the off ramp (see Photo 1, Photo 2, and Diagram). However, the slow lane was not completely blocked and temporary traffic control measures were not in place. After the victim positioned his vehicle, it is believed that he grabbed a flashlight and was walking around the front of his vehicle to begin directing traffic onto the off ramp. At this time, an approaching motorist, allegedly impaired, drove around the victim's vehicle, striking the victim as he stepped into the slow lane. Shortly after being fatally struck, personnel from the victim's department arrived on scene in E63. 
Volunteer Fire Chief Struck and Killed on Interstate Highway While Directing Traffic - Pennsylvania

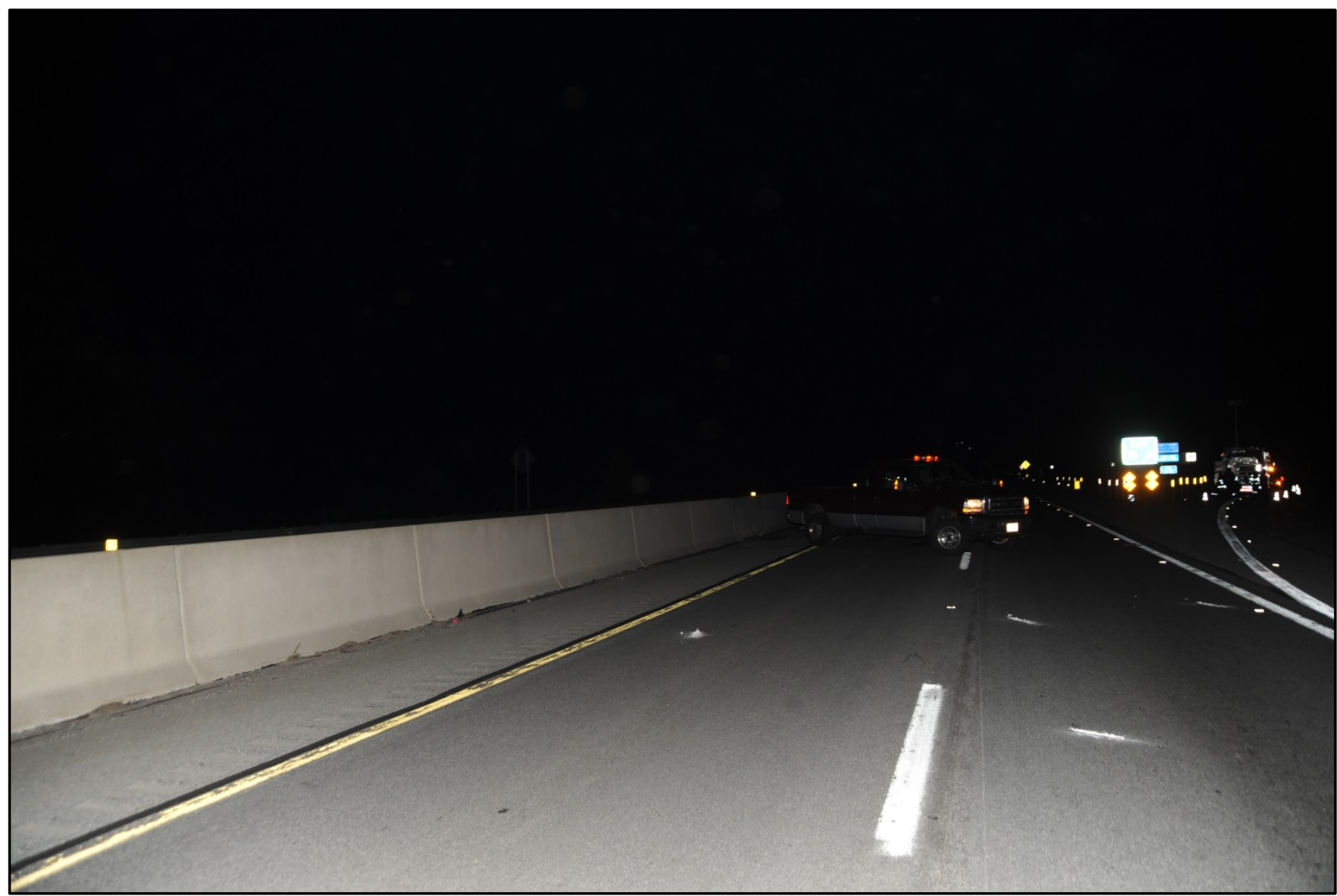

Photo 2. Photo shows placement of the victim's vehicle at time he was struck and the mini-light bar still activated.

(Photo courtesy of law enforcement.) 
Volunteer Fire Chief Struck and Killed on Interstate Highway While Directing Traffic - Pennsylvania

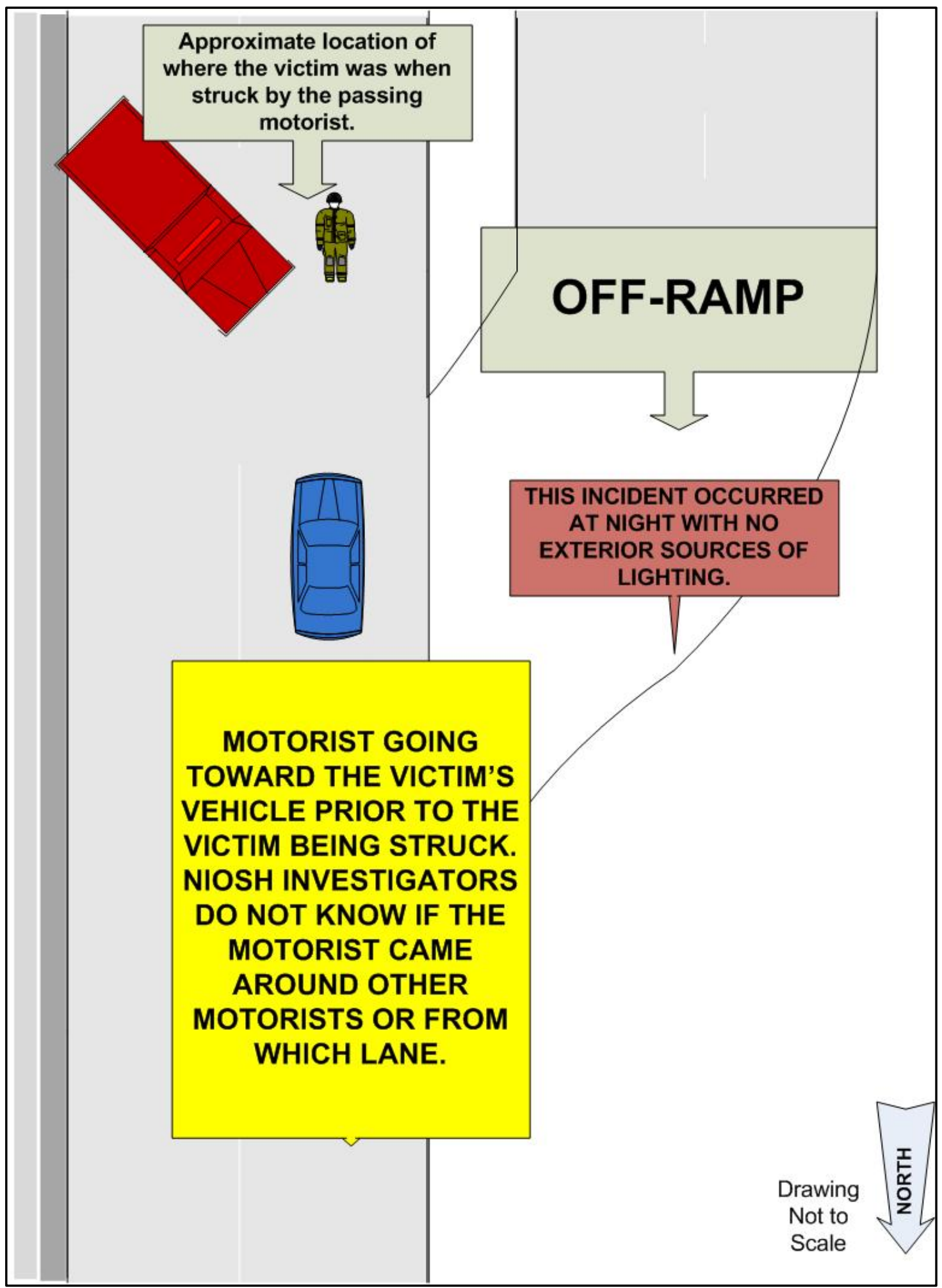

Diagram. Depiction of the incident just prior to the victim being struck by the motorist. 


\section{Volunteer Fire Chief Struck and Killed on Interstate Highway While Directing Traffic - Pennsylvania}

\section{Contributing Factors}

Occupational injuries and fatalities are often the result of one or more contributing factors or key events in a larger sequence of events that ultimately result in the injury or fatality. NIOSH investigators identified the following items as key contributing factors in this incident that led to the fatality:

- Victim working in an unprotected travel lane

- Lack of advanced warning to oncoming traffic

- Inconspicuousness of victim and vehicle

- Alleged impaired motorist.

\section{Cause of Death}

According to the coroner's report, the coroner listed the victim's cause of death as due to blunt force injuries sustained in a collision between a pedestrian and a motor vehicle.

\section{Recommendations}

Recommendation \#1: Fire departments should ensure that emergency responders receive training, and have adequate staffing, sufficient equipment, and appropriate procedures in place for responding to roadway emergency incidents.

Discussion: All responders that have the potential of being assigned to traffic control duties should be trained in: the use of advanced warning devices; safe-positioning of department apparatus; use of highvisibility personal protective equipment (PPE) at all roadway incidents noting the limitations of such PPE during fire suppression and hazardous material type incidents; available/necessary resources (e.g., personnel, vehicles, equipment), general safety practices, and establishment of the traffic incident management area (TIMA). Training should be provided to all emergency responders before responding to a roadway incident.

The Manual on Uniform Traffic Control Devices (MUTCD) is a resource for establishing temporary traffic control. MUTCD Chapter 6I, " - Control of Traffic Through Incident Management Areas,” defines a traffic incident management area as "an area of highway where temporary traffic controls are installed, as authorized by a public authority or the official having jurisdiction of the roadway, in response to a road user incident, natural disaster, hazardous material spill, or other unplanned incident. ${ }^{1}$ It is a type of temporary traffic control (TTC) zone and extends from the first warning device (such as a sign, light, or cone) to the last TTC device or to a point where vehicles return to the original lane alignment and are clear of the incident." 1 Also, according to the MUTCD, traffic incidents can be divided into three general classes of duration, each of which has unique traffic control characteristics and needs. These classes are listed below:

A. Major-expected duration of more than 2 hours

B. Intermediate- expected duration of 30 minutes to 2 hours 


\section{Volunteer Fire Chief Struck and Killed on Interstate Highway While Directing Traffic - Pennsylvania}

\section{Minor—expected duration under 30 minutes}

Due to the potential duration of this incident it would have been classified as an intermediate traffic incident. These types of incidents require traffic control on scene to divert traffic past the incident and may also require full roadway closures for short periods to allow emergency responders time to accomplish their tasks. MUTCD guidance for intermediate traffic incidents states that all TTC devices needed to set up the area should be available so that they can be readily deployed. The TIMA should include the proper traffic diversions, tapered lane closures, and upstream warning devices to alert traffic approaching the queue and to encourage early diversion to an appropriate alternative route. Attention should be paid to the upstream end of the traffic queue such that warning is given to road users approaching the back of the queue. If manual traffic control is needed, it should be provided by qualified flaggers or uniformed law enforcement officers. ${ }^{1}$

Warning devices and transition areas are a means by which emergency personnel can convey information to motorists approaching an incident scene, referred to as the "advance warning area." Warning devices in the advance warning area may vary from a single sign or high-intensity rotating, flashing, oscillating, or strobe lights on a vehicle to a series of signs in advance of the incident scene. NFPA 1500 Standard on Fire Department Occupational Safety and Health Programs section 8.7.5 states that one or more of the following warning devices be used to warn oncoming traffic of the emergency operations and the hazards to members operating at the incident: (1) fluorescent and retroreflective warning devices such as traffic cones, (2) Federal Highway Administration approved 48-inch by 48-inch retro-reflective signs stating "Emergency Scene Ahead” (with directional arrow overlay), (3) illuminated warning devices such as highway flares, and (4) other devices appropriate to warn oncoming traffic of the emergency operations. ${ }^{2}$ Additionally, cones should be predominantly orange and should be made of a material that can be struck without causing damage to the impacting vehicle. For day time and low-speed roadways, cones should be not less than 18 inches in height. When cones are used on freeways and other high-speed highways or at night on all highways, or when more conspicuous guidance is needed, cones shall be a minimum of 28 inches in height with retro-reflective markings. ${ }^{2}$ NFPA 1500 section 8.7.6 states that warning devices should be placed and used with proper considerations given to visual obstruction, such as hills, curves, or blind spots, or unusual localized weather conditions, such as fog or rain. ${ }^{2}$ Weather conditions, curves, and hills that limit visibility of the incident scene require that the advance warning devices be placed at an even greater distance.

Portable signs or portable changeable message signs can be transported by an emergency vehicle to the incident scene where they can be placed in a location that allows maximum visibility to oncoming traffic. The MUTCD states "where special emphasis is needed, signs may be placed on both the left and right sides of the roadway. Signs mounted on portable supports may be placed within the roadway itself. Signs may also be mounted on or above barricades.”굴 primary purpose of portable changeable message signs is to advise the road user of unexpected situations such as changes in speed, visibility, or traffic pattern.

The roadway on which the incident occurred had a 65-mph posted speed limit. No TTC devices were available to establish the TIMA and warn approaching motorists. The victim used his personal vehicle 


\section{Volunteer Fire Chief Struck and Killed on Interstate Highway While Directing Traffic - Pennsylvania}

to partially block traffic lanes. All lanes should have been blocked to prevent motorists from traveling further into an incident scene downstream. The victim's vehicle was dark in color and did not contain retro-reflective stripping; however, the mounted red mini-light bar was activated. The interstate highway was also dark with limited or no roadway illumination (see Photo 2). These conditions could cause motorist difficulties in identifying a change in traffic conditions. Also, the victim was entering the slow lane of the interstate from behind his vehicle without a high-visibility retro-reflective vest to direct approaching motorists to slow down, and move over. NFPA 1500 states that each department shall establish, implement, and enforce SOPs regarding emergency operations for traffic incidents. ${ }^{2}$ A model SOP for establishing advance warning and transition areas at roadway-related incidents can be found at

[http://www.respondersafety.com/Articles/Model_SOG_Available_for_Download_on_Deploying_Co nes_and_flares_at_Roadway_Incidents.aspx. $]^{3}$

The National Fire Protection Association (NFPA) is currently drafting a standard titled, NFPA 1091 Standard on Professional Qualifications for Traffic Control Incident Management. This document will provide emergency responders with information related to safe operations at a roadway incident. A draft copy of NFPA 1091 can be found at http://www.nfpa.org/AboutTheCodes/AboutTheCodes.asp?docnum=1091\&tab=nextedition. Fire departments need to remember that personnel used for traffic control purposes should receive training that is commensurate with their duties and in accordance with any applicable state and local laws and regulations. ${ }^{2}$ For more information related to training, PPE, and policies/procedures, see the “Additional Information" section at the end of this report.

\section{Recommendation \#2: Fire departments should ensure that standard operating guidelines include guidance on identifying and maintaining a safe location while working in or near moving traffic.}

Discussion: Emergency responders should operate defensively with an awareness of the high risk associated with working in or near moving traffic, because responders cannot rely on approaching motorists to see them, slow down, and/or move over. Motorists may ignore traffic signs and regulations for various reasons, including poor visibility, distraction, being under the influence of alcohol or drugs, and/or because of a medical condition that affects their judgment or abilities. This line-of-duty death provides a reminder that emergency responders can never depend solely on lights, and a blocking vehicle to protect them when they are working near moving traffic. Fire departments need to ensure that multiple prevention strategies are in place and emergency responders must maintain situational awareness at all times to what is going on around them. NFPA 1500 states fire departments should make every effort to protect members from conflict with motor vehicle traffic. ${ }^{2}$ Fire departments should train members on how to identify hazardous situations and preplan an escape strategy should they encounter a dangerous traffic situation, such as a vehicle entering the temporary traffic control zone. ${ }^{4}$ The placing of advanced warning devices to aid oncoming traffic in recognition of a TIMA may not provide emergency service personnel with complete protection from traffic hazards. Personnel should remain in an area of safety created by the proper positioning of apparatus and warning devices. A fire department vehicle with emergency lights flashing provides additional warning and additional protection to the incident scene. 


\section{Volunteer Fire Chief Struck and Killed on Interstate Highway While Directing Traffic - Pennsylvania}

During this incident, the victim was struck while standing in an unprotected travel lane as he was preparing to direct traffic to the off ramp. The fire department had an existing SOG that stated that personal vehicles would not be used to physically block traffic. Also, the motorist was allegedly under the influence.

\section{Recommendation \#3: Fire departments should establish pre-incident plans and agreements regarding traffic control and incident management at roadway incidents with other fire departments, EMS, law enforcement, local or state departments of highways, and private sector responders.}

Discussion: Pre-incident planning is fundamental to effective traffic control incident management. The white paper Protecting Emergency Responders on the Highways ${ }^{\underline{5}}$ states that a preplan should (1) account for possible use of detours, (2) anticipate the likelihood of vehicles transporting hazardous materials or of extraordinary weight or size, (3) accommodate the need to keep commerce flowing, (4) minimize the possibility of secondary incidents, and (5) account for possible impact on neighboring jurisdictions. All agencies that may respond to motor vehicle incidents should be fully involved in the process, formatting, and developing of pre-incident plans, and ensure that the final plan is easily understood and implemented within their agency. ${ }^{6}$

According to the U.S. Fire Administration document, Traffic Incident Management Systems, ${ }^{7}$ specific concepts that should be addressed in pre-incident planning for roadway incident operations include the following:

- All agencies that may respond to roadway incidents should be fully involved in the development of the plan and ensure that the final plan is easily understood and implemented within their agency.

- Each agency involved must provide initial and refresher training and ensure that individual and organizational roles are understood.

- Each agency should make sure that personnel are at least minimally briefed on the roles and procedures of other plan participants to avoid on-scene confusion and conflict.

Local authorities, including law enforcement, departments of transportation, fire departments, municipal leadership, businesses, and other interested parties, should work together to develop local traffic control incident management plans that address the needs of the local community in the event of traffic disruptions. These traffic control incident management plans should address a wide range of events that could affect normal roadway traffic, such as traffic incidents, hazardous material spills, fires, natural disasters, inclement weather, parades, and other events. States and municipalities, including the transportation department, in conjunction with fire departments, emergency medical responders, law enforcement, and private sector responders (e.g., tow truck operators), should develop these plans to include automatic response protocols detailing responsibilities of each at roadway incidents. Governing entities should ensure that adequate funding is available to staff and equip emergency response protocols once jointly established and agreed upon by all parties involved. 


\section{Volunteer Fire Chief Struck and Killed on Interstate Highway While Directing Traffic - Pennsylvania}

Preplanning such incidents allows fire departments and other interested parties to identify needs, locate sources of necessary resources and materials, and develop mutual-aid-response agreements.

Prior to this incident, no pre-incident plans and agreements had been established.

\section{Recommendation \#4: Fire departments should ensure that apparatus equipped with high-visibility chevrons and reflective markings are used for blocking to enhance conspicuity and protection of emergency scenes while operating at highway incidents}

Discussion: Highway incident scene safety has been at the forefront of efforts to reduce fire fighter death and injury. Several initiatives to increase conspicuity of emergency apparatus have been finalized and guidance has been provided to assist fire departments in implementing these procedures..$^{\underline{8}}$ NFPA 1901 Standard for Automotive Fire Apparatus was revised and became effective in January 2009. Its purpose is to enhance visibility of emergency vehicles that are parked along roadways during emergency incidents. Chapter 1.3.1 states, “ This standard shall apply to new fire apparatus that meet the following criteria: (1) that have $10,000 \mathrm{lb}(4500 \mathrm{~kg}$ ) or greater gross vehicle weight rating (GVWR) or are trailers intended to be towed by fire apparatus under emergency response conditions, (2) that are designed for use under emergency conditions to transport personnel and equipment and to support the suppression of fires and mitigation of other hazardous situations, or (3) that are contracted for on or after January 1, 2009.”모 The specific marking requirements are outlined in NFPA 1901 Chapters 15.9.3.1 and 15.9.3.2 states "A retro-reflective stripe(s) shall be affixed to at least 50 percent of the cab and body length on each side, excluding the pump panel areas, and at least 25 percent of the width of the front of the apparatus. The stripe or combination of stripes shall be a minimum of 4 inches (100 $\mathrm{mm}$ ) in total width. At least 50 percent of the rear-facing vertical surfaces, visible from the rear of the apparatus, excluding any pump panel areas not covered by a door, shall be equipped with retroreflective striping in a chevron pattern sloping downward and away from the centerline of the apparatus at an angle of 45 degrees.”- Additional information and requirements related to vehicle markings, required protective ensembles, and traffic control devices can be found within NFPA 1901.

NFPA 1901 applies to newly manufactured apparatus and is not retroactive. However, in many cases it can be cost effective and easy to retrofit existing apparatus to improve fire fighter emergency work zone safety. Fire departments should consider putting reflective tape on apparatus doors, on fixed sections that are not blocked by doors or ladder racks, and around the bottom of the apparatus. A video detailing guidance for retrofitting apparatus with the newly recommended safety lighting and markings can be found on the Emergency Responder Safety Institute website, http://www.respondersafety.com/MarkedAndSeen.aspx. .10 Roadway incident response safety procedures call for fire apparatus to park on an angle at roadway incident scenes to create a work area that is protected from passing traffic. Often apparatus emergency lighting is not as effective when parked at an angle. A more effective design calls for emergency lights to be mounted up high on the back of the apparatus to provide $360^{\circ}$ visibility. Amber lighting on the rear of apparatus can be very effective at warning motorists of an active emergency work zone. Amber lights convey a message of caution and motorists are accustomed to slowing down for amber warning lights in highway construction work zones. $\frac{10}{}$ 


\section{Volunteer Fire Chief Struck and Killed on Interstate Highway While Directing Traffic - Pennsylvania}

During this incident, the victim arrived on scene first and used his personal vehicle, marked solely with an oscillating red mini-light bar, to block and assist with diverting traffic off the interstate. The victim's vehicle did not have high-visibility reflective markings or chevrons. The fire department had an existing SOG that stated that personal vehicles would not be used to physically block traffic.

\section{Recommendation \#5: Fire departments should ensure that all personnel working at highway incidents wear the appropriate personal protective clothing and equipment, to include high-visibility retro-reflective material.}

Discussion: The need to wear personal protective equipment that includes high-visibility retroreflective striping and trim arises from the fact that personnel need to be highly visible while operating at highway incidents. Fire department personnel should wear the appropriate clothing that is referenced in the fire departments SOGs and if relevant, required by state laws. Additionally, the fire department should provide each member with the appropriate protective clothing and protective equipment to provide protection from the hazards to which the member is or is likely to be exposed. Such protective clothing and protective equipment shall be suitable for the tasks that the member is expected to perform. ${ }^{2}$ All emergency responders who are not involved in fire suppression activities should be wearing ANSI approved high-visibility retro-reflective garments when working near on highways.

To meet minimum requirements for high-visibility apparel, responders should only use vests that meet a Class II requirement of ANSI/ISEA 107-2010 (or subsequent revisions) or the requirements of ANSI/ISEA 207-2006 for Public Safety Vests. These minimum requirements include: 1) use of fluorescent background material, 2) the fluorescent material may be yellow-green, orange-red, or red, 3) retro-reflective material arranged for 360 degree visibility, and 4) the garments should be labeled as compliant with ANSI/ISEA 107-2010 or ANSI/ISEA 207-2006. Federal Regulation 23 CFR 634 states, "The purpose of the regulations in this part is to decrease the likelihood of worker fatalities or injuries caused by motor vehicles while working within the right-of-way on Federal-aid highways."

NFPA 1500 Standard on Fire Department Occupational Safety and Health Program states, "When members are operating at a traffic incident and their assignment places them in potential conflict with motor vehicle traffic, they shall wear a garment with fluorescent and retro-reflective material visible from all directions." $=$ All responders who are not involved in fire suppression activities should be wearing ANSI compliant high visibility garments when working near moving traffic and don the retroreflective vests during scene clean-up following extinguishment.

It should also be noted that in June 2009, the Federal Highway Administration (FHWA) adopted as final, an Interim Final Rule that amended its regulations to address safety concerns raised by the firefighting community regarding high-visibility safety apparel. $\stackrel{11}{ }$ The purpose of adopting the Interim Final Rule as final was to reflect the exemption of fire fighters from the requirement to use highvisibility safety apparel, as defined in 23 Code of Federal Regulations, Part 634, when exposed to hazardous conditions where the use of such apparel may increase the risk of injury to firefighter personnel. In other words, fire fighters who are engaged in firefighting and other emergency response 


\section{Volunteer Fire Chief Struck and Killed on Interstate Highway While Directing Traffic - Pennsylvania}

activities are not required to wear hi-visibility safety vests, if the vest would interfere with the performance of their activities, such as donning a self-contained breathing apparatus or present an additional hazard, such as increased risk of burn injuries.

During this incident, the victim was wearing street clothes and his structural firefighting coat (tan with standard high-visibility retro-reflective striping), but no high-visibility retro-reflective vest.

Recommendation \#6: Motorists should be attentive at all times, especially when approaching and driving through a traffic incident management area, so that they avoid striking emergency responders, other vehicles, and/or traffic control devices.

Discussion: Motorists need to maintain a constant awareness of their surroundings while operating a motor vehicle. They need to pay attention to such things as signs, emergency scenes, traffic patterns, work zones, and various roadway hazards (e.g., slowed/stopped vehicles, weather, and animals). Motorists should not be driving under the influence of any substance and should obey state laws.

Additionally, motorists could benefit from additional incident related information disseminated by other sources. Various means of disseminating incident related information to affected motorists are listed below:

- Commercial radio broadcasts

- Highway advisory radio

- Variable message signs

- In-vehicle or personal data assistant information or route guidance systems

- Commercial and public television traffic reports

- Changeable message boards

Traffic reports on radio and television stations have been a traditional means by which motorists receive traffic information, including incident-related warnings. Radio and television stations receive the traffic information they use in their reports from a variety of sources, which may include public transportation agencies, or by monitoring emergency (police and fire) radio frequencies.

Public agencies, radio, and television stations can communicate important incident-related information to motorists. This information may help motorists be more prepared for what's ahead and perhaps avoid the incident scene. Motorist information should be disseminated as soon as possible and should continue beyond the time it takes to clear an incident. This may take hours if an incident occurs during a peak traffic period or, has regional impacts. $\underline{12}$

\section{References}

1. FWHA [2009]. Part 6, Temporary traffic control elements. In: Manual on uniform traffic control devices (MUTCD). 2009 ed. Washington, DC: U.S. Department of Transportation, Federal Highway Administration [http://mutcd.fhwa.dot.gov/pdfs/2009/part6.pdf]. Date 


\section{Volunteer Fire Chief Struck and Killed on Interstate Highway While Directing Traffic - Pennsylvania}

accessed: July 2013.

2. NFPA [2013]. NFPA 1500 standard on fire department occupational safety and health program. 2013 ed. Quincy, MA: National Fire Protection Association.

3. ERSI [2009]. Model standard operating guideline (SOG) for cone, flare, or sign deployment at traffic related incidents. By Moore R. Berkeley Springs, WV: Cumberland Valley Volunteer Firemen’s Association, Emergency Responder Safety Institute [http://www.respondersafety.com/Articles/Model_SOG_Available_for_Download_on_Deployi ng_Cones_and_Flares_at_Roadway_Incidents.aspx]. Date accessed: July 2013.

4. NIOSH [2007]. Volunteer fire fighter dies when struck by a bus while working along an interstate highway - Illinois. Morgantown, WV: U.S. Department of Health and Human Services, Centers for Disease Control and Prevention, National Institute for Occupational Safety and Health, FACE Report No. F2007-26.

[http://www.cdc.gov/niosh/fire/reports/face200726.html]. Date accessed: July 2013.

5. CVVFA [1999]. Protecting emergency responders on the highways. By Chen HS, Austin S, Berkeley Springs, WV: Cumberland Valley Volunteer Firemen’s Association [http://www.respondersafety.com/DownloadCategories/White_Papers.aspx]. Date accessed: July 2013.

6. NFPA [2010]. NFPA 1620 standard for pre-incident planning. 2010 ed. Quincy, MA: National Fire Protection Association.

7. USFA [2008]. Traffic incident management systems. Emmitsburg, MD: Federal Emergency Management Agency, US Fire Administration.

8. ERSI [2009]. Innovations in apparatus conspicuity. By Sullivan J. Berkeley Springs, WV: Cumberland Valley Volunteer Firemen's Association, Emergency Responder Safety Institute [http://www.firerescue1.com/print.asp?act=print\&vid=508854]. Date accessed: July 2013.

9. NFPA [2009]. NFPA 1901 standard for automotive fire apparatus. 2009 ed. Quincy, MA: National Fire Protection Association.

10. ERSI [no date]. Marked and seen. Video. Berkeley Springs, WV: Cumberland Valley Volunteer Firemen's Association [http://www.respondersafety.com/MarkedAndSeen.aspx]. Date accessed: July 2013.

11. Code of Federal Regulations [2009]. Title 23 code of federal regulations (CFR), part 634 worker visibility (high-visibility vests). Federal Register Notice 28160, Volume 74, No. 113, Monday, June 15, 2009. 


\section{Volunteer Fire Chief Struck and Killed on Interstate Highway While Directing Traffic - Pennsylvania}

12. FHA [2000]. Traffic incident management handbook. By Farradyne PB. Washington, DC: U.S. Department of Transportation, Federal Highway Administration, Office of Travel Management. [http://ntl.bts.gov/lib/jpodocs/rept_mis/13286.pdf]. Date accessed: July 2013.

\section{Investigator Information}

This incident was investigated by Stacy C. Wertman, Safety and Occupational Health Specialist with the Fire Fighter Fatality Investigation and Prevention Program, Surveillance and Field Investigations Branch, Division of Safety Research, NIOSH located in Morgantown, WV. An expert technical review was provided by Steve Austin of the Cumberland Valley Volunteer Firemen's Association and Emergency Responder Safety Institute. A technical review was also provided by the National Fire Protection Association, Public Fire Protection Division.

\section{Additional Information}

Emergency Responder Safety Institute http://www.respondersafety.com/

Manual on Uniform Traffic Control Devices http://mutcd.fhwa.dot.gov/

National Traffic Incident Management Coalition

http://www.transportation.org/Default.aspx?SiteID=41

U.S. Department of Transportation, Federal Highway Administration http://ops.fhwa.dot.gov/eto_tim_pse/about/tim.htm

International Association of Fire Fighters Best Practices for Emergency Vehicle and Roadway Operations Safety in the Emergency Services http://www.iaff.org/hs/EVSP/quides.html

Pennsylvania Department of Transportation Temporary Traffic Control Guidelines Publication 213 http://www.firepolicepa.org/Articles/PUB_213.pdf

\section{Disclaimer}

Mention of any company or product does not constitute endorsement by the National Institute for Occupational Safety and Health (NIOSH). In addition, citations to Web sites external to NIOSH do not constitute NIOSH endorsement of the sponsoring organizations or their programs or products. Furthermore, NIOSH is not responsible for the content of these Web sites. 